\title{
ASSOCIAÇÃO ENTRE COMPOSIÇÃO CORPORAL E HIPERTENSÃO ARTERIAL SISTÊMICA EM MULHERES IDOSAS
}

Letícia Mazocco; Pontifícia Universidade Católica do Rio Grande do Sul (PUCRS); lety.mazocco@gmail.com

Patrícia Chagas; Universidade Federal de Santa Maria (UFSM); patriciachagas@ufsm.br Carla Helena Augustin Schwanke; Pontifícia Universidade Católica do Rio Grande do Sul (PUCRS); schwanke@pucrs.br

\section{RESUMO}

Introdução: $\mathrm{O}$ excesso de peso está associado com doenças crônicas, entre elas a hipertensão arterial sistêmica (HAS). Objetivo: Verificar a associação de indicadores de composição corporal e HAS em mulheres idosas. Métodos: Foram incluídas no estudo idosas submetidas à absorciometria por dupla emissão de raios-X (DXA). Dados sociodemográficos e história de HAS foram coletados através de um questionário. $\mathrm{O}$ peso e a estatura foram aferidos em balança antropométrica para cálculo do IMC. A massa gorda e magra foram avaliadas por DXA. Foram utilizadas estatísticas descritivas, sendo as descrições feitas por medidas de frequência, médias e desvios-padrões. Para comparação das médias das variáveis quantitativas foi utilizado o teste $\mathrm{t}$ de Student. Resultados: Participaram do estudo 288 idosas com idade média de 67,6 55,8 anos, sendo a maioria casada $(60,1 \%)$ e aposentada $(93,1 \%)$. A escolaridade mais frequente foi entre 4 e 8 anos de estudo $(44,1 \%)$. A frequência de HAS foi de 63,2\% $(\mathrm{n}=182)$. Entre as idosas hipertensas, o IMC médio foi de $28,27 \pm 5,3 \mathrm{~kg} / \mathrm{m} 2$, a massa gorda total média foi de $27,33 \pm 10,4 \mathrm{~kg}$ e a massa magra total média de $36,53 \pm 4,6 \mathrm{~kg}$. Já entre idosas não hipertensas, o IMC médio foi de $26,42 \pm 3,7 \mathrm{~kg} / \mathrm{m} 2$, a massa gorda total média foi de $24,75 \pm 7,9 \mathrm{~kg}$ e a massa magra total média de $36,01 \pm 4,1 \mathrm{~kg}$. HAS foi associada com o IMC ( $p=0,001)$ e com a massa gorda $(p=0,018)$ e não teve associação com a massa magra $(p=0,335)$. Conclusão: Observou-se associação de HAS com níveis médios maiores de IMC e de massa gorda.

Palavras-chave: Hipertensão arterial; Índice de massa corporal; Composição corporal.

Agradecimentos: O presente trabalho foi realizado com apoio da Coordenação de Aperfeiçoamento de Pessoal Nivel Superior - Brasil (CAPES) - Código de Financiamento 001. 